\title{
The influence of the weld toe grinding and wig remelting weld toe rehabilitation techniques, on variable stresses, in case of cross fillet welds, reinforced with additional welding rows
}

\author{
Claudiu Babis ${ }^{1, *}$, Andrei Dimitrescu ${ }^{1}$, Gabriel Iacobescu ${ }^{1}$, Gheorghe Solomon ${ }^{1}$, and Oana \\ Chivu $^{1}$ \\ ${ }^{1}$ Politehnica University of Bucharest, Materials and Welding Technology Department, 313Splaiul \\ Independenței, 060042 Bucharest, Romania
}

\begin{abstract}
Variable stresses where the load value varies between a maximum and a minimum value, or varies the position in time, cause after accumulating a large number of load cycles in those structures, the emergence of drug fatigue. Fatigue is characterized by failure on values of the applied stress from the load cycles, below the material flow, values which in case of static stress would not have caused problems. Knowing that the variable stressed structures are sensitive to stress concentrators, the paper aims to highlight the influence of two techniques to reduce stress concentrator weld toe grinding and WIG remelting weld toe, on the behavior of variable tensile test of cross corner welded specimens, reinforced with additional welding rows.
\end{abstract}

\section{Introduction}

There are many types of welded structures like welded bridges, ship structures; aircraft structures; bodies of the vehicles that are stressed variable and in time, they are affected by the phenomenon of fatigue which causes failure to values below the flow limit [1-2].

Fatigue failure are specific to welded structures which have fillet welds, which shows the stress concentrators at the intersection between the base and the filler material. Reducing these stress concentrators is accomplished by applying two reconditioning techniques: weld toe grinding and WIG remelting weld toe on cross welded samples, from which the specimens are taken for the variable tests [3-4]. Both reconditioning techniques determine either by polishing or by WIG remelting the reduction of stress concentrators at the junction base material / filler, causing an increase fatigue lifetime of the structure on which it is applied.

We considered telling this research to be done on the cruciform fillet welded joints as a welded structure, this type of connection showing the biggest failure by fatigue susceptibility.

\footnotetext{
*Corresponding author: claudiubbs@gmail.com
} 
Research is extracted from a large study in which 5 cross welded samples were used denoted by A; B; C; D and E depending on the welding process used.

On all samples were applied the reconditioning techniques weld toe grinding and WIG remelting weld toe, then extracted samples for static and variable tests. [5-6].

The cruciform welded sample which is the subject of the sample with sign $\mathrm{C}$, was welded by manual welding process with coated electrode in horizontal position on vertical wall that was reinforced with additional welding lines.

\section{Experimental procedure}

The shape and size of welded sample $\mathrm{C}$ on which were applied two reconditioning techniques weld toe grinding and WIG remelting weld toe in order to reduce the tensile concentrator and implicitly to enlarge the fatigue lifetime are shown in figure 1.

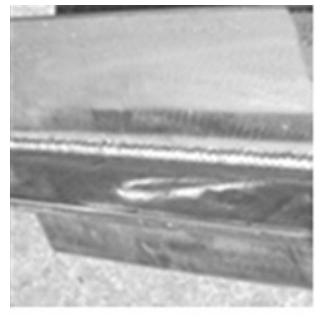

a-face plan welding sample

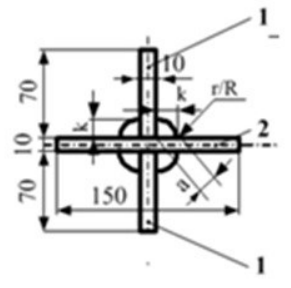

b- front view sketch welding sample

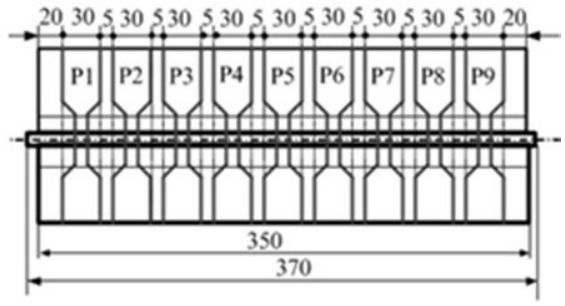

c-sampling areas specimens

Fig. 1. Shape and size of welding sample C

It is seen from Figure 1 that the welding sample $\mathrm{C}$ consists of two vertical components 1 and one horizontal component 2 .

Specimens C1; C4 and $\mathrm{C} 7$ will be subjected to static tensile testing static and are not subject to this paper, and specimens $\mathrm{C} 2$; $\mathrm{C} 3$; $\mathrm{C} 5$; $\mathrm{C} 6$; $\mathrm{C} 8$ and $\mathrm{C} 9$ will be subject to variable loads, the reconditioning techniques are applied before the test as follows: $\mathrm{C} 2$ and $\mathrm{C} 3$ without reconditioning; $\mathrm{C} 5$ and $\mathrm{C} 6$ with weld toe grinding and $\mathrm{C} 8$ and $\mathrm{C} 9$ with WIG remelting weld toe.

Fatigue testing specimens have been obtained by cutting the cross welded sample $\mathrm{C}$ yielding strips with width of $30 \mathrm{~mm}$ as shown Figure 1.c.

After mechanical cutting, vertical parts of the specimen attached to the horizontal plate will be milled to reduce the width from $30 \mathrm{~mm}$ to $10 \mathrm{~mm}$ in welding seams area, as shown in Figure 1.c. and Figure 2 a.

This milling is done in order to, during the variable loads to be submitted specimens, the section being reduced and the tensile increased on its surface, conduct the breaking in the seam or in the thermos-mechanical influenced area of the seam.

It is noticed that section is not reduced sharply from 30 to $20 \mathrm{~mm}$ but milling is done with a radius $\mathrm{R}=10 \mathrm{~mm}$, in order to not introduce additional stress concentrations. 


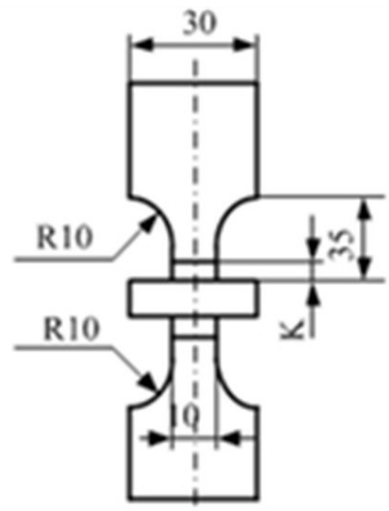

a-face plan

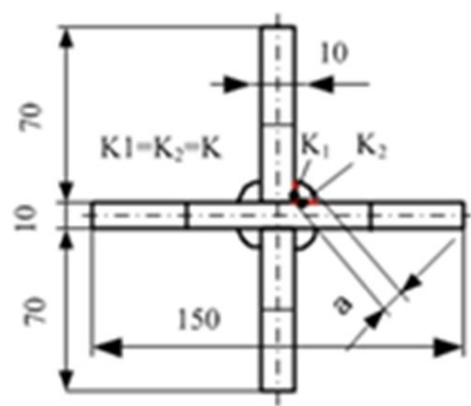

b-front view

Fig. 2. Specimen shape after milling

The specimens are made of steel type S 235 JR.

Welding regime parameters used to obtain sample $\mathrm{C}$ are shown in Table 1

Table 1. Welding regime parameters for sample $\mathrm{C}$

\begin{tabular}{|c|c|c|c|c|c|c|c|}
\hline Row & $\begin{array}{c}\text { Is } \\
{[\mathrm{A}]}\end{array}$ & $\begin{array}{c}\mathrm{Ua} \\
{[\mathrm{V}]}\end{array}$ & $\begin{array}{c}\mathrm{Ts} \\
{[\mathrm{s}]}\end{array}$ & $\begin{array}{c}\mathrm{Lc} \\
{[\mathrm{cm}]}\end{array}$ & $\begin{array}{c}\mathrm{vs} \\
{[\mathrm{cm} / \mathrm{s}]}\end{array}$ & $\begin{array}{c}\mathrm{Vas} \\
{[\mathrm{m} / \mathrm{min}]}\end{array}$ & $\begin{array}{c}\mathrm{El} \\
{[\mathrm{kJ} / \mathrm{cm}]}\end{array}$ \\
\hline $1-3$ & 220 & 19,9 & 85 & 35 & 0.41 & 5,3 & 7,67 \\
\hline
\end{tabular}

Breaking sections are presented below.

In Figure 3 are shown breaking sections for specimens $\mathrm{C} 2$ and $\mathrm{C} 3$ without reconditioning.

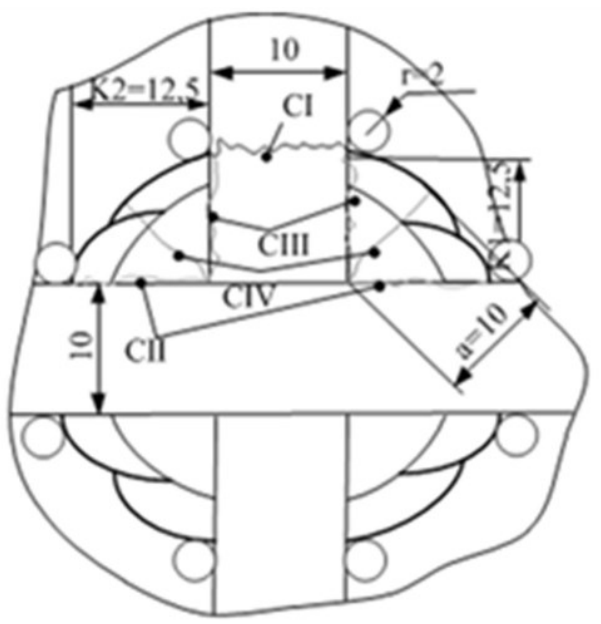

Fig. 3. Breaking sections for $\mathrm{C} 2$ and $\mathrm{C} 3$

In Figure 4 are shown schematically possible breaking sections in case of applied techniques weld toe grinding - Figure 4.a and WIG remelting weld toe - Figure 4.b. 

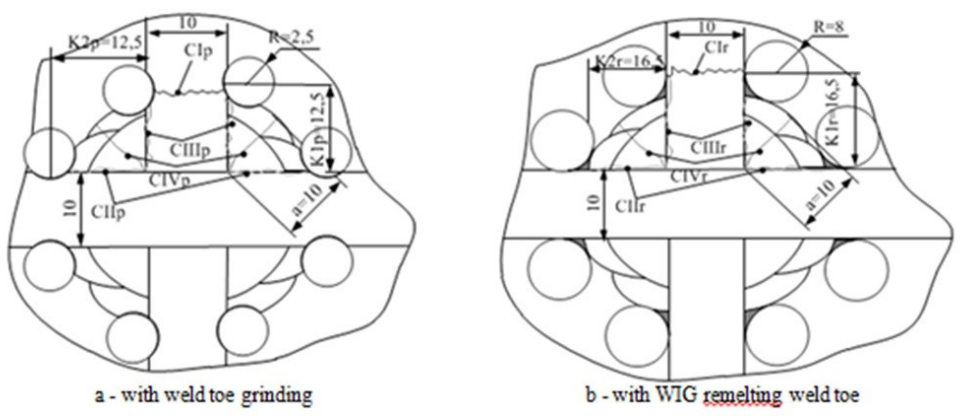

Fig.4. Breaking sections in case of applying the reconditioning

Geometric elements; K1; K2 and r of the welding seams of the specimens from sample $\mathrm{C}$ are shown in Table 2.

Table 2. Geometric elements of the welding seams - specimens sample $\mathrm{C}$

\begin{tabular}{|l|c|c|c|}
\hline Geometric element & $\begin{array}{c}\text { Without reconditioning } \\
\text { C2 si C3 }\end{array}$ & $\begin{array}{c}\text { weld toe grinding } \\
\text { C5 si C6 }\end{array}$ & $\begin{array}{c}\text { WIG remelting weld toe } \\
\text { C8 si C9 }\end{array}$ \\
\hline $\mathrm{a}$ & 10 & 10 & 10 \\
\hline $\mathrm{K} 1=\mathrm{K} 2$ & 12.5 & 12.5 & 16.5 \\
\hline $\mathrm{r}$ & 2 & 2.5 & 8 \\
\hline
\end{tabular}

where: $\mathrm{a}$ is the thickness of the welding seam; $\mathrm{K} 1$ and $\mathrm{K} 2$ are the seam legs and $\mathrm{r}$ is the radius between seam and base material.

Fatigue tests were carried out with LVF 1000-HM unit. All attempts were made at 10 $\mathrm{Hz}$ frequency, the loadd cycle being an symmetrical alternating one, with asymmetry coefficient $\mathrm{R}=-1$, the application being tensile-compression. For each set of specimens, with reconditioning techniques applied or not, they were raised durability curves that they have been compared to each other. For raising the durability curves were applied the the following loads variations, as follows: for $\mathrm{C} 2$; $\mathrm{C} 5$ and $\mathrm{C} 8 \pm 14 \mathrm{kN}$ and for $\mathrm{C} 3$; $\mathrm{C} 6$ and $\mathrm{C} 9$ $\pm 7,5 \mathrm{kN}$. The fatigue test samples are shown in figure 5 .

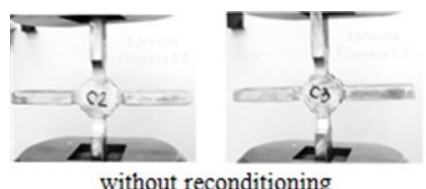

without reconditioning

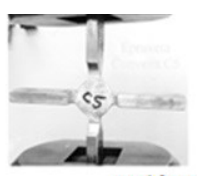

weld toe grinding

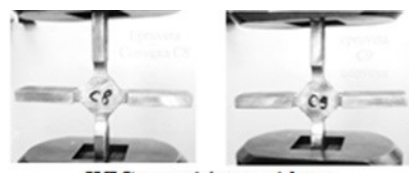

WIG remelting weld toe

Fig.5. The fatigue test samples

A few frames during fatigue tests for $\mathrm{C} 2$ and $\mathrm{C} 3$ samples without reconditioning, are presented in figure 6 .
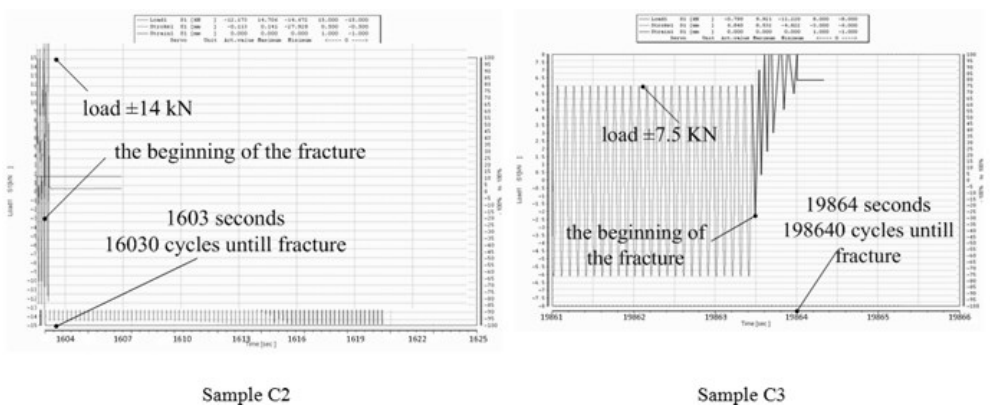

Fig.6. Frames for fatigue tests for $\mathrm{C} 2$ and $\mathrm{C} 3$ samples 
We observe that, with decreasing the solicitation applied force for samples $\mathrm{C} 3$ and $\mathrm{C} 2$, increase the number of cycles untill the fracture: 198640 cycles for $\mathrm{C} 3$ and 16030 cycles for C2.

Another two frames for fatigue tests in case of C5 and C6 samples with weld toe grinding applied technique are shown in figure 7.

We also aobserve that, with decreasing the solicitation applied force for samples C6 and C5, increase the number of cycles untill the fracture: 287992 cycles for C6 and 22400 cycles for $\mathrm{C} 5$.

The last two frames for fatigue tests for C8 and C9 samples with WIG remelting weld toe applied technique, are shown in figure 8.

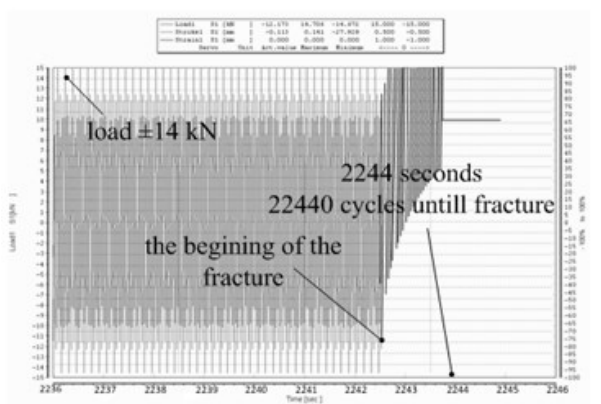

Sample C5

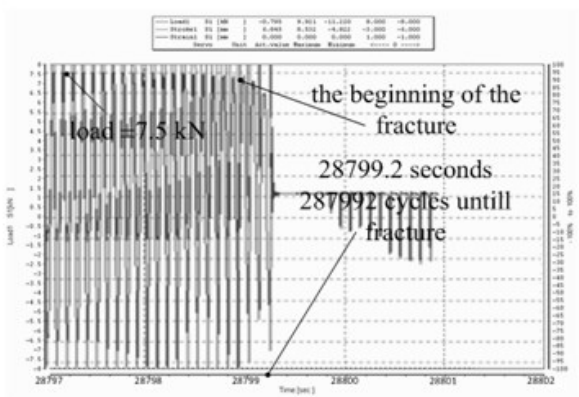

Sample C6

Fig.7. Frames for fatigue tests for C5 and C6 samples

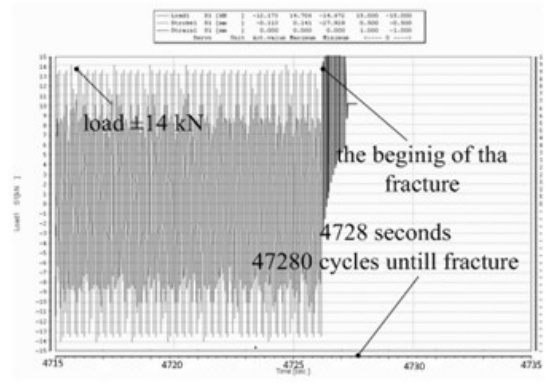

Sample C8

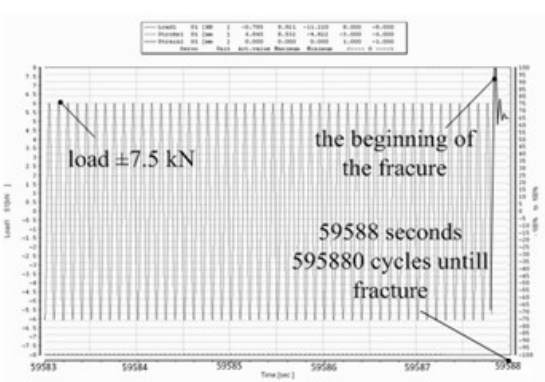

Sample C9

Fig.8. Frames for fatigue tests for $\mathrm{C} 8$ and $\mathrm{C} 9$ samples

\section{Results and discussions}

Forces applied to the specimens and results obtained from fatigue tests are presented centralized in table 3

Tabel 3. Results obtained from fatigue tests

\begin{tabular}{|c|c|c|c|c|c|}
\hline Denotation & Reconditioning & $\mathrm{F}[\mathrm{Hz}]$ & $+/ \mathrm{Fi}[\mathrm{KN}]$ & $\mathrm{t}[\mathrm{s}]$ & $\mathrm{N}$ \\
\hline $\mathrm{C} 2$ & \multirow[b]{2}{*}{ Without } & \multirow{6}{*}{10} & \pm 14 & 1603 & 16030 \\
\hline $\mathrm{C} 3$ & & & $\pm 7,5$ & 19864 & 198640 \\
\hline $\mathrm{C} 5$ & \multirow{2}{*}{$\begin{array}{l}\text { Weld toe } \\
\text { grinding }\end{array}$} & & \pm 14 & 2244 & 22440 \\
\hline C6 & & & $\pm 7,5$ & 28799.2 & 287992 \\
\hline $\mathrm{C} 8$ & \multirow[t]{2}{*}{ WIG remelting } & & \pm 14 & 4728 & 47280 \\
\hline C9 & & & $\pm 7,5$ & 59588 & 595880 \\
\hline
\end{tabular}


We notice that, with decreasing tensile stress on the samples $\mathrm{C} 2$ and $\mathrm{C} 3$, increases the number of cycles up to fracture. We mention that on specimens without reconditioning we have the highest value of stress concentrator at the junction welding seam / base material, because of the smallest radius connecting seam to the base material, namely $\mathrm{r}=2 \mathrm{~mm}$.

The sample C5 on which we apply $\pm 14 \mathrm{kN}$, was broken after 22440 cycles and C6 on which we have applied $\pm 7.5 \mathrm{kKN}$ broke after 287992 load cycles. We found an increase in the number of cycles compared to homologous specimens $\mathrm{C} 2$ and $\mathrm{C} 3$. This is explained by the reduction of the stress concentrator at the top of the seam connection by increasing the radius of 2 to $2.5 \mathrm{~mm}$ as shown in table 2

We also observed that the sample C8 on which we apply $\pm 14 \mathrm{kN}$, broke after 47280 cycles and the sample C9 on which we have applied $\pm 7.5 \mathrm{KN}$, broke after 595880 load cycles. We determinate an increase in the number of cycles compared to the homologous C5 and C6 specimens. This is also explained by the stress concentrators reduction at the top seam according to table 2, by increasing the radius from 2.5 to $8 \mathrm{~mm}$.

Radii measurements were made with a specialized software by entering the crosssections pictures of the specimens, scale 1:1.

\section{Conclusions}

Conclusions can be drawn after raising the durability curves from figure 9, with Mathcad calculation program.

With Mathcad calculation program, for samples $\mathrm{C} 2$ and C3, without technical reconditioning, we found values $\mathrm{p}=2$ and $\mathrm{r}=6.7$, for which the chart function $\sigma 1 c(n)$, approaching most of our points $\mathrm{cl}=(16030 ; 40027 ; 198$ 649) and $\mathrm{f}$ representing force vector $f=(14 ; 9 ; 6)$. The shape of this curve is show in figure 9 with dashed point line.

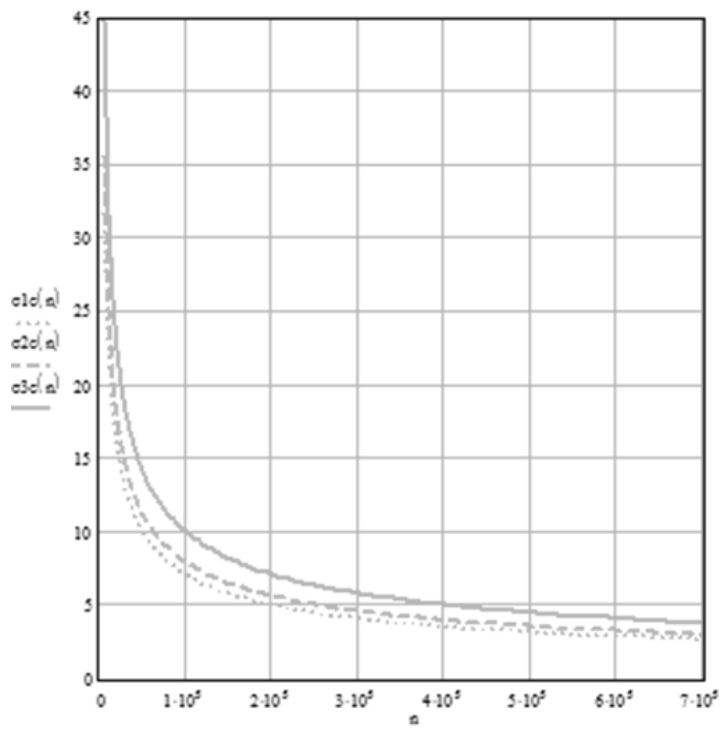

Fig.9. Raising the durability curves with Mathcad program

For the second set of samples C5 and C6, with weld toe grinding rehabilitation technique applied, with Mathcad software, were found the values $\mathrm{p}=2$ and $\mathrm{r}=6.8$ for the function chart, approached most of our points $c 2=(22440 ; 56038 ; 287991)$ and force vector $\mathrm{f}=(14 ; 9 ; 6)$. The shape of this curve is shown also in figure 9 with all dashed line. 
For the third set of samples C8 and C9, on which we have applied WIG remelting weld toe, with the Mathcad software, were found the values $\mathrm{p}=2$ and $\mathrm{r}=6.5$ where the function chart is closest to our points $\mathrm{c} 3=(47281 ; 118080 ; 595888)$ and the force vector $\mathrm{f}=$ $(14 ; 9 ; 6)$. The shape of this curve is shown in figure 9 with continuous line.

\section{References}

1. H.-K. Juna, J.-W. Seoa, I.-S. Jeonb, S.-H. Leec, Y.-S. Chang, Engineering Failure Analysis, 59, 478-492 (2016)

2. J. Barle, , , V. Grubisic a, b, F. Vlak 3. Engineering Failure Analysis, 18, 3, 1076-1084 (2011)

3. R. Baptistaa, V. Infanteb, C.M. Brancob. International Journal of Fatigue (2008)

4. H. C. Yildirım. International Journal of Fatigue (2015)

5. D. T. Ngoula, H.Th. Beier, M. Vormwald. International Journal of Fatigue (2016)

6. T. Skriko, M. Ghafouri, T. Björk. International Journal of Fatigue (2017) 